\title{
A case report on decidual cast following B-lynch compression suture
}

Laleeta Meena, Suman Budania*

Department of Obstetrics and Gynecology, Sardar Patel Medical College, Bikaner, Rajasthan, India

Received: 03 May 2021

Revised: 12 June 2021

Accepted: 14 June 2021

*Correspondence:

Dr. Suman Budania,

E-mail: drbudsum@gmail.com

Copyright: (C) the author(s), publisher and licensee Medip Academy. This is an open-access article distributed under the terms of the Creative Commons Attribution Non-Commercial License, which permits unrestricted non-commercial use, distribution, and reproduction in any medium, provided the original work is properly cited.

\begin{abstract}
In case of atonic postpartum haemorrhage (PPH) and traumatic PPH or cervical tear extended deep up to lower uterine segment exploratory laparotomy is the last resort to control PPH. It was a case of 20 years old female admitted in labour room with chief complain of bleeding per vaginum and something coming out of vagina after 6 weeks of post laprotomy for atonic postpartum hemorrhage. Compression sutures were applied and bilateral uterine artery ligation was done at time of laparotomy. After 6 weeks post laparotomy the patient was presented with complain of something coming out from vagina. An examination was performed under short general anesthesia in the operation theater, the mass was removed without any resistance. A provision diagnosis of decidual cast was made which was later confirmed by histopathological report which shows autolytic changes in decidual tissue. Women which are undergoing bilateral uterine artery ligation or compression suture for management of postpartum hemorrhage, should be informed about potential complication. Postoperative follow-up is necessary for any complications.
\end{abstract}

Keywords: Decidual cast, PPH, B-lynch compression suture

\section{INTRODUCTION}

Obstetrical hemorrhage is the leading cause for maternal mortality worldwide. Primary postpartum hemorrhage occurs in $4-6 \%$ of pregnancies and is caused by uterine atonicity in $80 \%$ of the cases. ${ }^{1}$ Primary postpartum haemorrhage (PPH) has been controlled by various medical and surgical methods, which include use of uterotonic agents, uterine massage, bimanual uterine compression, uterine tamponade, uterine packing, stepwise devascularization, uterine artery embolization, compression sutures and obstetric hysterectomy. This article reports an interesting case of a decidual cast following the application of B-lynch uterine compression sutures. Decidua is endometrium that is hormonally prepared for pregnancy. Decidual cast is the entire sloughed endometrium that takes the form of the endometrial cavity. It may be associated with ectopic pregnancy, incomplete abortion, non-pregnant state with use of progesterone, depot medroxyprogesterone acetate
(DMPA), rarely with oral contraceptive pills. ${ }^{2}$ The theory of hyper-progesteronism has been hypothesized and cases have been observed of decidual cast expulsion following progesterone. Other theories proposed by Greenblatt include an overall increase in the secretion of progesterone and estrogen, subsequent thickening of the endometrium and resultant in complete desegregation with expulsion of tissue; excessive development of the spiral arteries, with subsequent vasodilatation followed by vasoconstriction and then shedding of this overdeveloped endometrium. ${ }^{3}$

\section{CASE REPORT}

Our patient was 20 year old women primigravida with period of gestation 32 week presented to emergency department with complain of pain abdomen delivered a preterm baby by assisted breech delivery vaginally. After delivery the patient have atonic postpartum hemorrhage which was not control by medical treatment for which she immediately taken for laparotomy bilateral uterine artery 
was ligated and B-lynch compression suture was applied. PPH was controlled and patient was discharged after recovery. 6 weeks following post laparotomy patient was again admitted with complain of bleeding per vaginum and something coming out of vagina. Ultrasound was done which was suggestive of multiple linen foci which gives dirty note in endometrial cavity and upper vaginal wall s/o endometritis. She was taken in operation theater for examination, on per abdomen examination, abdomen was soft and stich line was healthy with no other abnormalities, in per vaginal examinations, a mass was protruding from vagina which was remove without resistance. On gross examination it was approx. $10 \times 7 \times 0.5 \mathrm{~cm}$ in size and brown colored, dry with some black colored area in between. The tissue was saved and sent for histopathological examination.

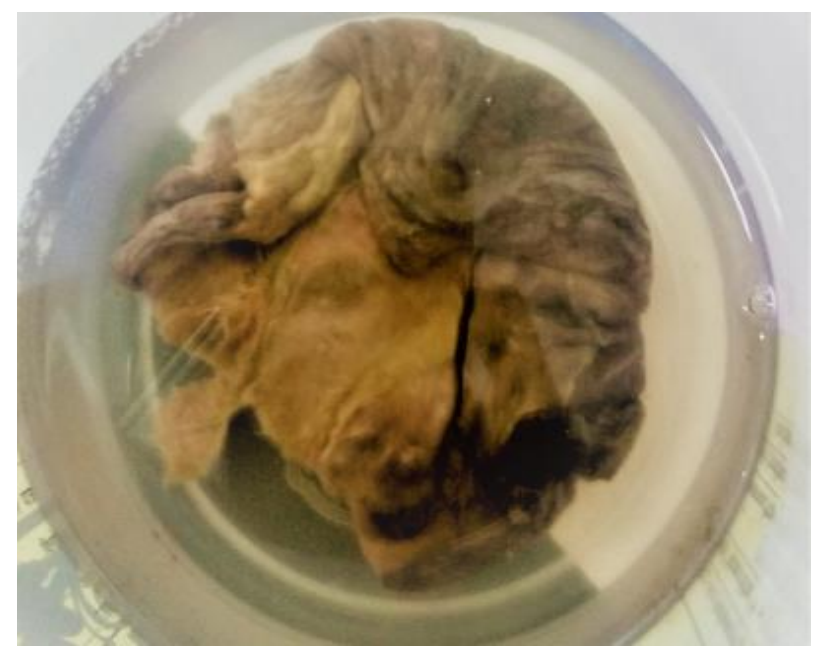

Figure 1: Decidual cast expelled in this case.

Histopathology report suggestive of decidua with autolytic changes.

\section{DISCUSSION}

The lining of the pregnant uterus, other than the area taken up by the placenta, is called the decidua. The appearance of the normal lining of the uterus, by the effect of progesterone, becomes decidualized. When an area of decidua is shed, it is called a decidual cast because it frequently comes out in the shape of the uterine cavity. Decidual casts have a well know association with ectopic pregnancies.PPH is unpredictable, no women are exempt from the risk of PPH. Prompt diagnosis, rapid action, and a multidisciplinary approach are crucial for preventing and managing PPH. Compression suture techniques have shown great promise in decreasing maternal morbidity and mortality associated with uterine atony, while maintaining fertility. ${ }^{4}$ Lynch et al described a novel technique of a uterine compression suture placed vertically as "belt and braces"; this suturing method was applied successfully in 5 patients as an alternative to cesarean hysterectomy. ${ }^{5}$ In 2000, Cho et al published an article about a case series of 23 patients with primary $\mathrm{PPH}$ who were treated by multiple square sutures compressing the anterior and the posterior walls of their uterus. ${ }^{6}$ In 2002, Hayman placed two vertical sutures on each side of the uterus in each of 3 patients who had $\mathrm{PPH} .^{7}$ The rationale for all the improved methods is based on hemodynamic studies, which have shown that uterine compression sutures reduced pelvic blood flow and the surface area of uterine wall and thus prompt hemostasis. The reported complications resulting from these sutures are pyometra, uterine synechiae, uterine necrosis, partial ischemic necrosis, and, in a few of the procedures, hysterectomy was not averted because the sutures "slid off" at the uterine fundus, and uterine avulsion occurred after the knots were tied too tightly. ${ }^{9} \mathrm{~A}$ review by Grote gut et al reported 3 failures in 35 patients who received B-lynch suturing, a success rate of $91.4 \% .^{8}$ In a 7-year prospective case series of 28 patients, Baskett reported a success rate of $82 \% .{ }^{9} \mathrm{He}$ observed the presence of grooves over the uterine fundus at the site of previous B-lynch sutures in 3 of seven patients who had subsequent cesarean sections after the initial compression sutures. Joshi and Srivastava described a case of severe postpartum hemorrhage in a 26-year-old primigravida who developed disseminated intravascular coagulopathy in the immediate postoperative period. ${ }^{10}$ After partial correction of the disseminated intravascular coagulopathy, the patient underwent a laparotomy. The surgeons found that the Blynch suture had cut through and become embedded in the patient's uterine wall, causing ischemic congestion and distension of the mid-section of her uterus between the Blynch vertical braces, giving her uterus a lobulated appearance. ${ }^{11}$ Akoury and Sherman are the first authors to describe focal myometrial necrosis following the use of simultaneous B-lynch and Cho-square suture.

Treloar et al reported the use of the B-lynch suture to control severe PPH in a 33-year-old multigravida. ${ }^{12}$ Over following 3 postpartum weeks, the woman experienced persistent vaginal bleeding and was found to have a tender sub involuted uterus of 18-weeks' size. Magnetic resonance imaging (MRI) with and without intravenous gadolinium contrasting, revealed that her uterus was avascular, except at the peripheral rim of the uterine wall.

\section{CONCLUSION}

Decidual casts have a well-known association with ectopic pregnancies. In non-pregnant women, decidual casts has been reported in patients taking human menopausal gonadotropin, human chorionic gonadotropin and progesterone. Unpredictable effects on endometrial and myometrial vasculature could be produced by compressive forces of uterine compression sutures like B-lynch compression suture, Cho suture, bilateral uterine artery ligation and other hemostatic suture applied to control postpartum hemorrhage. If the blood supply of the inner myometrium and endometrium is disrupted, then decidua may be shed in form of a cast, as occurred in my case. So, patient should be informed about potential complications and postoperative follow up. 


\section{ACKNOWLEDGMENTS}

Authors believe that it is of utmost importance to express sense of gratitude to guide Dr. Suman Budania who guided in this work.

Funding: No funding sources

Conflict of interest: None declared

Ethical approval: Not required

\section{REFERENCES}

1. Combs CA, Murphy EL, Laros RK. Factors associated with postpartum haemorrhage with vaginal birth. Obstet Gynecol. 1991;77:69.

2. Omar, Smith. Membranous Dysmenorrhea. Sci World J. 2007;7:1900-3.

3. Greenblatt RB, Hammond MD, Clark SL. Membranous dysmenorrhea: Studies in aetiology and treatment. Am J Obstet Gynecol. 1954;68:835-44.

4. B-Lynch C, Coker A, Lawal AH, Abu J, Cowen MJ. The B-Lynch surgical technique for the control of massive post- partum haemorrhage: An alternative to hysterectomy? Five cases reported. Br J Obstet Gynaecol. 1997;104:372.

5. Cho JH, Jun HS, Lee CN. Hemostatic suturing technique for uterine bleeding during caesarean delivery. Obstet Gynecol. 2000;96:129.
6. Hayman RG, Arul Kumaran S, Steer PJ. Uterine compression sutures: Surgical management of postpartum haemorrhage. Obstet Gynecol. 2002;99:502.

7. Zhenag J, Xiong X, Ma Q, Zhang X, Li M. A new uterine compression suture for postpartum haemorrhage with atony. BJOG. 2011;118:370.

8. Grotegut CA, Larsen FW, Jones MR, Livingston E. Erosion of a B-Lynch suture through the uterine wall: A case report. J Reprod Med. 2004;49:849.

9. Baskett TF. Uterine compression sutures for postpartum haemorrhage: Efficacy, morbidity, and subsequent pregnancy. Obstet Gynecol. 2007;110:68.

10. Joshi VM, Srivastava M. Partial ischemic necrosis of the uterus following a uterine brace compression suture. BJOG. 2004;111:279.

11. Akoury H, Sherman C. Uterine wall necrosis following combined B-Lynch and Cho square sutures for the treatment of primary PPH. J Obstet Gynecol Can. 2008;30:421.

12. Treloar EJ, Anderson RS, Andrews HS, Bailey JL. Uterine necrosis following B-Lynch suture for primary PPH. BJOG. 2006;113:486.

Cite this article as: Meena L, Budania S. A case report on decidual cast following B-lynch compression suture. Int J Reprod Contracept Obstet Gynecol 2021;10:2921-3. 